\title{
New Era of Percutaneous Endoscopic Lumbar Surgery: Lumbar Stenosis Decompression - A Technical Report
}

\author{
Gun Choi ${ }^{1}$, Ketan Deshpande ${ }^{1}$, Akarawit Asawasaksakul', SH Lee \\ ${ }^{1}$ Department of Neurosurgery, Seoul Gimpo Airport Wooridul Hospital \\ ${ }^{2}$ Department of Neurosurgery, Seoul Wooridul Hospital
}

\begin{abstract}
The next step in expanding the indications of percutaneous endoscopic lumbar discectomy is management of lumbar canal stenosis via endoscopic approach. Technical advances in the endoscopic instruments especially endodrill [burr], and endoscopic punch are allowing the spine surgeons to take on the challenge of lumbar decompression by the most minimally invasive approach possible. But the procedure is still in developmental phases with indications limited to selective cases. We wish to present a technical report and brief discussion about the current application of endoscopy in lumbar canal stenosis.
\end{abstract}

Keywords: Endoscopy; Percutaneous; Lumbar spine; Stenosis

\section{History}

In 1934, Mixter and Barr [1] reported first successful microdiscectomy; Minimally Invasive Spine Surgery (MISS) has been developing continuously since then. Janssen and Val [2] isolated Chymopapain from Papaya and Smith et al. [3], in 1964, successfully used it to treat patients with prolapsed disc percutaneously. Afterwards in 1974, Hijikata [4] reported a non-invasive discectomy using a tubular retractor under local anesthesia, followed by Onik and Marron [5] with their automated nucleotome in 1985 , which led to even lesser tissue dissection. In 1986, Kambin and Sampson [6] introduced an image amplifier in percutaneous discectomy to help needle placement, this made percutaneous procedure much more accurate than before. Kambin also, in 1990, described anatomic safe zone for arthroscopic microdiscectomy known as Kambin's triangle [7] and a year later he reported $87 \%$ success rate in this procedure.

In 1992, Lee et al. [8] developed percutaneous endoscopic laser discectomy by combination of advantage from arthroscopic microdiscectomy and the use of laser for discectomy, and the success rate of $93 \%$ could be achieved. In 1996, Mathews and 1998, Ditsworth [9] opened the endoscopic era via transforaminal approach by reporting success in foraminoscopic procedures.

Since then, there were many studies that contributed in extending the indications of endoscopic spinal surgery for other spinal pathologies such as spinal stenosis. In 1996, Kambin and Zhou [10], in their study about lateral recess stenosis decompression using mechanical tools and 0 degree, 30 degree scopes, made a way in application of endoscope in treating spinal stenosis. Similarly, Martin Knight in 2001 [11] described the technique for foraminoplasty using Ho-YAG laser. Yong Ahn et al. have established the technique for L5-S1 foraminal and lateral zone stenosis [12]. In 2004, Choi Gun et al. [13] published the first scientific paper on interlaminar technique application. Choi Gun et al have also demonstrated other applications of percutaneous endoscopy in situations like down migrated disc, up migrated disc, extra-foraminal disc and approaches like trans-iliac and contra-lateral [14-19]. Today interlaminar approach is extended to include various canal stenosis pathologies. In his recent article on treating canal stenosis Dr. Yong Ahn has reviewed various percutaneous approaches [20].

\section{Choice of patient}

Indications

- Clinical criterion included lower limb radiculopathy or claudication from neurologic origin with or without back-pain not responding to conservative treatment

- Radiological criterion included the evidence of stenosis on computed tomography, and/or magnetic resonance imaging correlating the clinical presentation

Contra-indications

- Degenerative spondylolysthesis (grade 2 or more)

- $\quad$ Profound neurodeficit (weakness grade 4-5)

- Cauda equina syndrome

\section{Technical aspects}

Approach- depending on the location and the type of the pathology, the approach can be either

- Transforaminal, or

- Interlaminar

Armamentarium

- $\quad$ Endoscope

\begin{tabular}{|l|c|c|c|}
\hline & Angle & Length & Working channel \\
\hline Transforaminal & $25-30$ degree & $210 \mathrm{~mm}$ & $3.7 \mathrm{~mm}$ \\
\hline Interlaminar & $25-30$ degree & $165 \mathrm{~mm}$ & $3.7 \mathrm{~mm}$ \\
\hline
\end{tabular}

- Working cannula - length $170 \mathrm{~mm}$, outer diameter $7.5 \mathrm{~mm}$ (circular, or beveled tip)

- Interlaminar serial dilators

\begin{tabular}{|c|c|c|}
\hline Number & Diameter & Length \\
\hline 1 & $1 \mathrm{~mm}$ & $26 \mathrm{~cm}$ \\
\hline
\end{tabular}

*Corresponding author: Ketan Deshpande, Department of Neurosurgery, Seoul Gimpo Airport Wooridul Hospital, South KoreaOffice: 82-2-2660-7788Fax: 82-22660-7599; E-mail: ketan228@gmail.com

Received August 12, 2014; Accepted September 18, 2014; Published September 20, 2014

Citation: Choi G, Deshpande K, Asawasaksakul A, Lee SH (2014) New Era of Percutaneous Endoscopic Lumbar Surgery: Lumbar Stenosis Decompression - A Technical Report. J Spine 3: 182. doi:10.4172/2165-7939.1000182

Copyright: ( 2014 Choi G, et al. This is an open-access article distributed under the terms of the Creative Commons Attribution License, which permits unrestricted use, distribution, and reproduction in any medium, provided the original author and source are credited. 


\begin{tabular}{|l|l|l|}
\hline 2 & $2 \mathrm{~mm}$ & $23 \mathrm{~cm}$ \\
\hline 3 & $4 \mathrm{~mm}$ & $19 \mathrm{~cm}$ \\
\hline 4 & $5 \mathrm{~mm}$ & $16 \mathrm{~cm}$ \\
\hline
\end{tabular}

- $\quad$ Endoscopic forceps - working length $320 \mathrm{~mm} \&$ diameter $3.5 \mathrm{~mm}$

- $\quad$ Endoscopic punch - working length $320 \mathrm{~mm}$ \& diameter 3.5 $\mathrm{mm}$

- $\quad$ Endoscopic scissors

- $\quad$ Endoscopic drill/ burr -diamond tip 2,2.5 mm

- Endoscopic shaver

- $\quad$ Radiofrequency cautery (RF)

- Ho-YAG laser with side firing probe

- A blunt tip probe

Classification- for all practical purposes canal stenosis can be divided either based on

- Location

- Central

- Lateral recess

- Foraminal

- Type

- Bony

- $\quad$ Soft tissue

- $\quad$ Combined

Table 1 and 2 briefly summarize the classification and the choice of approach for various stenotic pathologies

\section{Central stenosis}

Central stenosis predominantly results from hypertrophied ligamentum flavum but sometimes can be the result of mild flavum hypertrophy in combination with small contained disc herniation or rarely congenital stenosis superimposed with some flavum hypertrophy [21] or diffuse idiopathic skeletal hypertrophy syndrome [22]. In either case the choice of approach remains constant i.e. interlaminar and

\begin{tabular}{|c|c|}
\hline \multicolumn{2}{|c|}{ Stenosis } \\
\hline Location & Type \\
\hline Central & Bony \\
Lateral recess & Soft tissue \\
Foraminal & Combined \\
\hline
\end{tabular}

Table 1: Briefly summarize the classification and the choice of approach for various stenotic pathologies.

\begin{tabular}{|l|c|c|c|c|}
\hline Location & Type & Etiology & Level & Choice of Approach \\
\hline Central & Either & Either & Either & Interlaminar \\
\hline \multirow{3}{*}{ Lateral } & \multirow{2}{*}{ Recess } & Superior facet & L1 to L5 & Transforaminal \\
\cline { 3 - 6 } & & L5-S1 & Interlaminar > Transforaminal \\
\cline { 3 - 6 } & Soft tissue & Either & Either & Interlaminar \\
\cline { 2 - 5 } & Combined & Either & Either & Interlaminar \\
\hline Foraminal & Either & Either & Either & Transforaminal \\
\hline
\end{tabular}

Table 2: Briefly summarize the classification and the choice of approach for various stenotic pathologies. the presenting complaint determines the extent of decompression. A patient with central stenosis can present with predominant unilateral radicular leg pain or bilateral neurologic claudication. In our experience for central stenosis with unilateral radiculopathy, central + symptomatic side decompression is usually sufficient, but a patient with bilateral symptoms needs contra-lateral decompression as well.

\section{Technique}

Anesthesia - conscious sedation (with Propofol and Remifentanyl) supplemented with a caudal block

Position - prone with hips and knees in flexion and abdomen supported over bolsters

Level marking - target level end-plates and the interlaminar window are roughly marked under fluoroscopic guidance

Entry point - approximately midway between the spinous process and the lateral extension of the interlaminar window (Figure 1)

Skin infiltration - with $1 \%$ lidocaine approximately $2-3 \mathrm{cc}$

Target point - base of spinous process of proximal vertebra in antero-posterior (AP) view and posterior to the lamina in lateral (LAT) view

Needle insertion - from the mentioned entry point an 18G $90 \mathrm{~mm}$ spinal needle is directed towards the base of the spinous process in slightly medial and cranial direction till it reaches the desired point in both AP and LAT views

Serial dilation - a blunt tip guide wire is inserted and after a skin incision of approximately 9 to $10 \mathrm{~mm}$, the tract is serially dilated till the $4^{\text {th }}$ dilator (Figures 2 and 3 ) under fluoroscopic guidance, a circular working cannula is passed over the final dilator and the scope is passed through it

The complete procedure is performed under continuous pressure irrigation using cold, antibiotic instilled normal saline. RF is used initially to clear the fat and para-spinal soft tissue and to enhance visibility. Decompression is begun by locating the junction of the superior lamina and the base of the spinous process (SP). An endodrill is used to burr out the base of the SP and the drill is slowly moved laterally over the ipsilateral lamina (Figures 4 and 5). Care should be taken during drilling that the drill should always remain in the centre of the endoscopic view and to do that the surgeon should move the endoscope and the endo-drill synchronously. It is advisable to keep

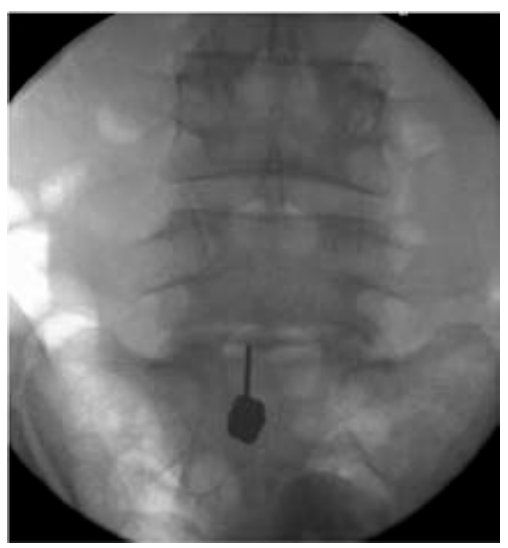

Figure 1: Needle entry in central decompression - interlaminar approach. 
Citation: Choi G, Deshpande K, Asawasaksakul A, Lee SH (2014) New Era of Percutaneous Endoscopic Lumbar Surgery: Lumbar Stenosis Decompression - A Technical Report. J Spine 3: 182. doi:10.4172/2165-7939.1000182
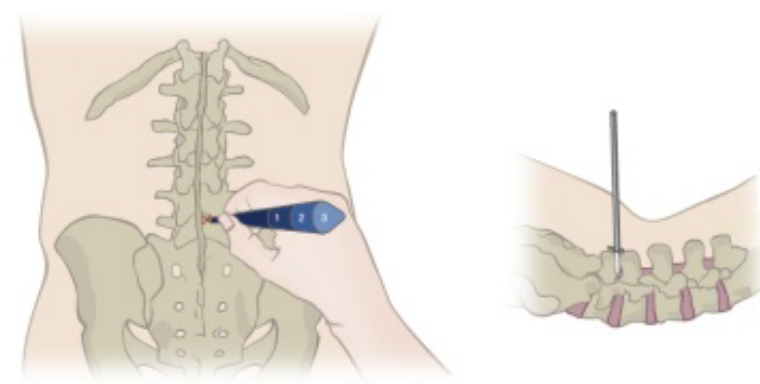

Figure 2: Showing serial dilation in AP and LAT views.

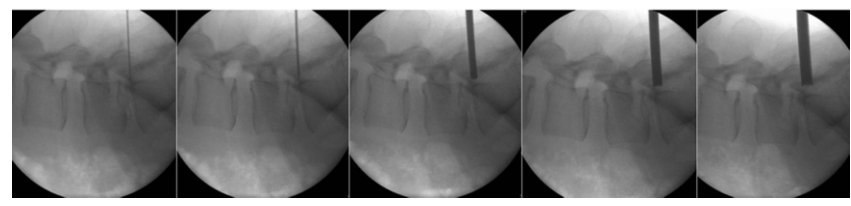

Figure 3: Serial dilators on c-arm lateral view.

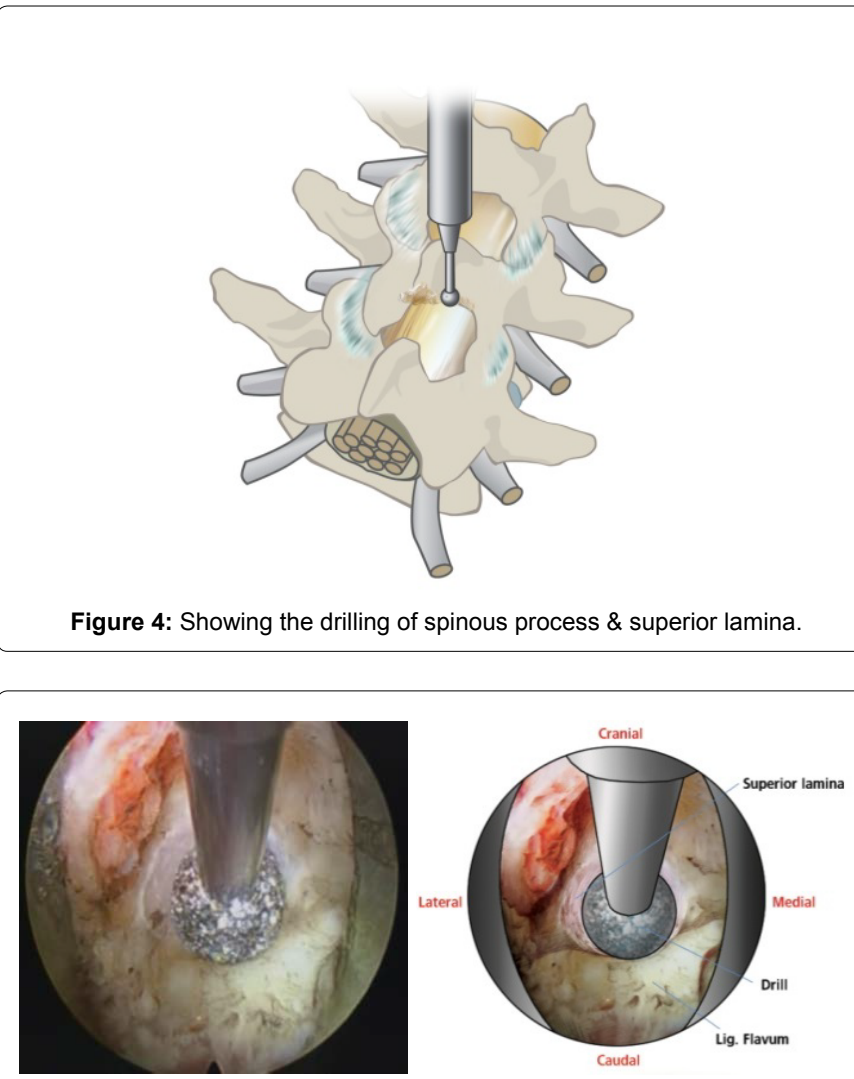

Figure 5: Endoscopic view of drilling of lamina in interlaminar approach.

the ligamentum flavum intact till the end of bony decompression as it acts to shield the thecal sac and protect it from any inadvertent injury. Soft tissue decompression begins by making an opening in the flavum which can be done either with a blunt tip probe or endoscopic scissors. The opening is further widened using an endo punch or a side-firing laser. The extent of decompression can be checked by confirming the position of the instruments under fluoroscopy in both AP and LAT views. As previously stated, contra-lateral decompression is needed in patients with bilateral symptoms. In these cases the base of the spinous process can be drilled more to create additional space to access the contra-lateral lamina. Central stenosis cases do not require discectomy as post-operatively the thecal sac along with its contents will fall posteriorly away from the disc, so we can keep the disc intact. Also in majority of the cases visualization of the traversing root is not essential but can be easily visualized if need arises, by tilting the scope laterally. At this stage one can replace the circular cannula with a beveled cannula and use the beveled end as a root retractor to get a visual confirmation of the adequacy of decompression (Figure 6). Haemostasis is achieved using the RF cautery and a hemo-vac drain can be inserted with a single stay suture at the skin.

\section{Lateral recess stenosis}

Lateral recess is the space bordered laterally by the pedicle, dorsally by the superior articular facet, and ventrally by the posterior surface of the vertebral body. The height of lateral recess (from posterior surface of the vertebral body to the ventral portion of the superior articular facet should be more than $3 \mathrm{~mm}$. Lateral recess stenosis can be the result of superior facetal hypertrophy, or ligamentum flavum hypertrophy, or osteophyte from the vertebral body. In rare cases of degenerated spondylolysthesis it can be the result of forward movement of the inferior facet directly compressing the nerve root. The presenting symptom of the patient is unilateral neurogenic claudication.

Depending on the etiology and the target level, the choice of approach may vary (Table 2 ).

\section{Technique}

1. Interlaminar - there are two aspects of choosing an interlaminar approach to perform lateral recess decompression, (a) Ipsilateral interlaminar and (b) Contra-lateral interlaminar, with both the techniques having their own advantages and limitations (Table 3).

\section{Ipsilateral interlaminar}

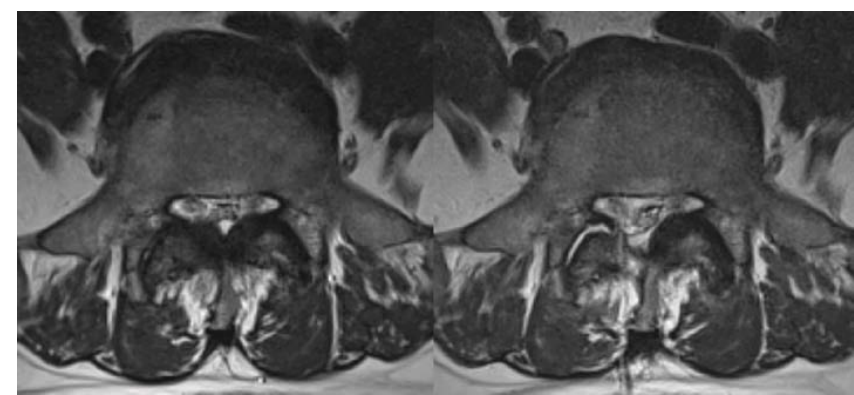

Figure 6: Pre and post -operative axial views in central stenosis interlaminar approach.

\begin{tabular}{|c|c|}
\hline Contra-lateral interlaminar & Ipsilateral interlaminar \\
\hline $\begin{array}{l}\text { - } \\
\text { - } \\
\text { - } \\
\text { Goose of access to lateral recess } \\
\text { decompression for central base of spinous } \\
\text { process and superior lamina can } \\
\text { be accessed }\end{array}$ & $\begin{array}{l}\text { - } \quad \text { Maximum soft tissue preservation } \\
\text { - } \quad \text { Ramiliar approach } \\
\text { - } \quad \text { painful } \\
\text { - Needs more facetal decompression }\end{array}$ \\
\hline
\end{tabular}

Table 3: Pros \& Cons of both interlaminar approaches in lateral recess decompression. 


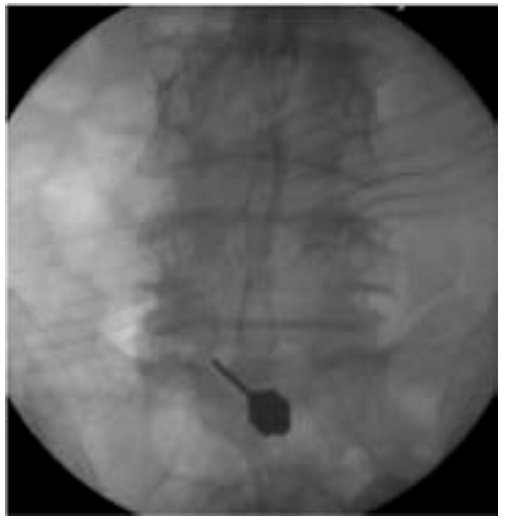

Figure 7: Interlaminar ipsilateral lateral recess approach - needle entry.

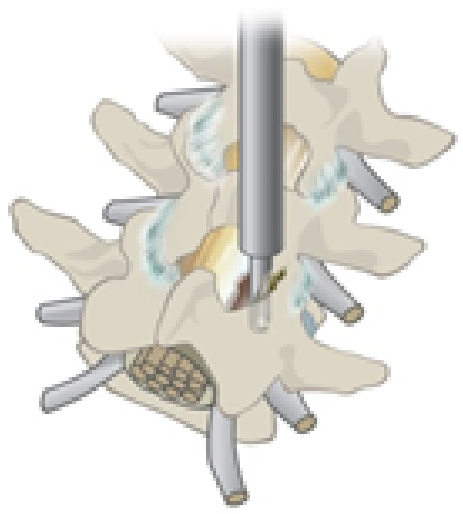

Figure 8: Showing use of arthroscopic shaver in lateral recess.

Anesthesia - general anesthesia is preferred

Position - prone with hips and knees in flexion and abdomen supported over bolsters

Level marking - target level end-plates and the interlaminar window are roughly marked under fluoroscopic guidance 7)

Entry point - lateral most point of the interlaminar window (Figure

Target point - lateral end of the proximal lamina in AP and posterior to the lamina in LAT view c-arm

Needle insertion - from the mentioned entry point an 18G $90 \mathrm{~mm}$ spinal needle is directed towards the junction of the lamina with the facet till it reaches the desired point in both AP and LAT views

Serial dilation - a blunt tip guide wire is inserted and after a skin incision of approximately 9 to $10 \mathrm{~mm}$, the tract is serially dilated till the $4^{\text {th }}$ dilator under fluoroscopic guidance (Figure 3), a circular working cannula is passed over the final dilator and the scope is passed through it

After soft tissue clearance with RF cautery the lamino-facetal junction is identified and endo-drill is used to burr out the hypertrophied facet and the lateral lamina. An arthroscopic shaver also comes handy as it comes with an anterior protective sleeve (Figure 8). Ligamentum flavum is cut in similar fashion and the opening widened. The next critical step is to identify and isolate traversing root. If sufficient bony decompression is already achieved then traversing root can be easily located but if not, then further bony decompression has to be undertaken with a shaver till root is sufficiently visualized. In cases with flavum hypertrophy a sidefiring laser can be used to achieve decompression. Once the traversing root is identified, the circular cannula is replaced with a beveled cannula and the beveled end is used to isolate the root medially away from the surgical field. Further decompression can be safely continued using a shaver (Figure 9) or a diamond burr and discectomy can be performed if needed. The end point of procedure is the visual confirmation of the free traversing root. Wound is closed with a single skin suture over hemovac drain. (Figures 10a-d) demonstrate animations to summarize this approach.

\section{Contra-lateral interlaminar}

Anesthesia - general anesthesia is preferred

Position - prone with hips and knees in flexion and abdomen supported over bolsters

Level marking - target level end-plates and the interlaminar window are roughly marked under fluoroscopic guidance

Entry point - approximately midway between spinous process and the lateral extension of the interlaminar window on the asymptomatic
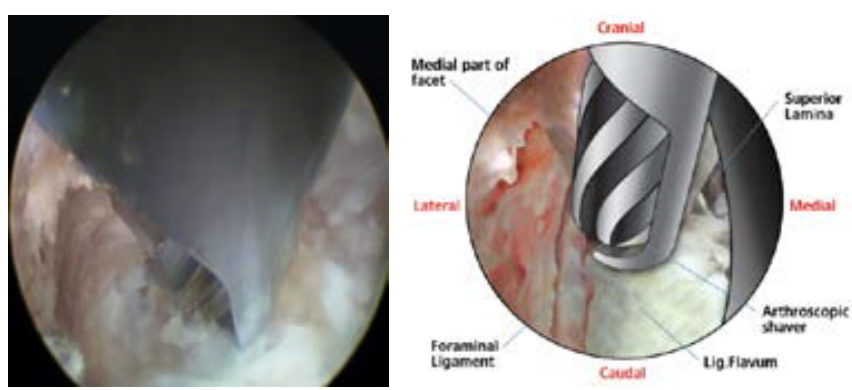

Figure 9: Endoscopic view of shaver in lateral recess.
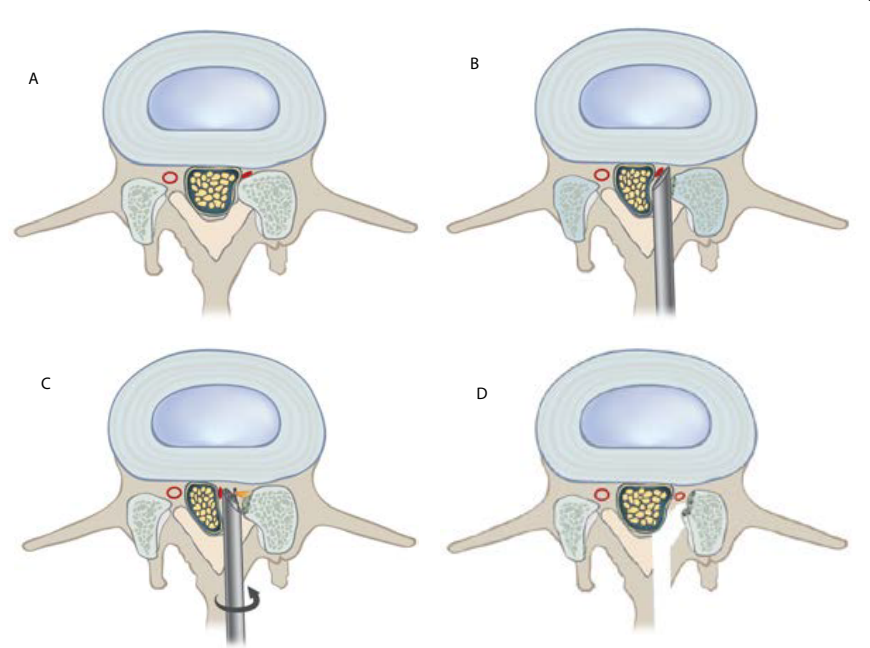

Figure 10: a: Lateral recess stenosis.

b: Insertion of beveled cannula.

c: Rotating the beveled cannula to protect the traversing root and decompression of the lateral recess.

d: Decompressed lateral recess with free traversing root. 
Citation: Choi G, Deshpande K, Asawasaksakul A, Lee SH (2014) New Era of Percutaneous Endoscopic Lumbar Surgery: Lumbar Stenosis Decompression - A Technical Report. J Spine 3: 182. doi:10.4172/2165-7939.1000182

Page 5 of 8

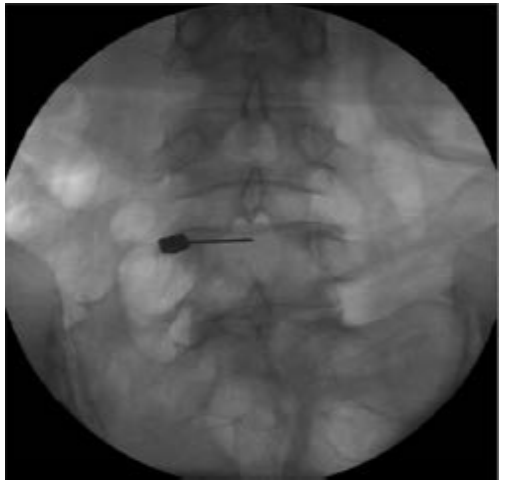

Figure 11: Interlaminar contra-lateral lateral recess approach - needle entry.
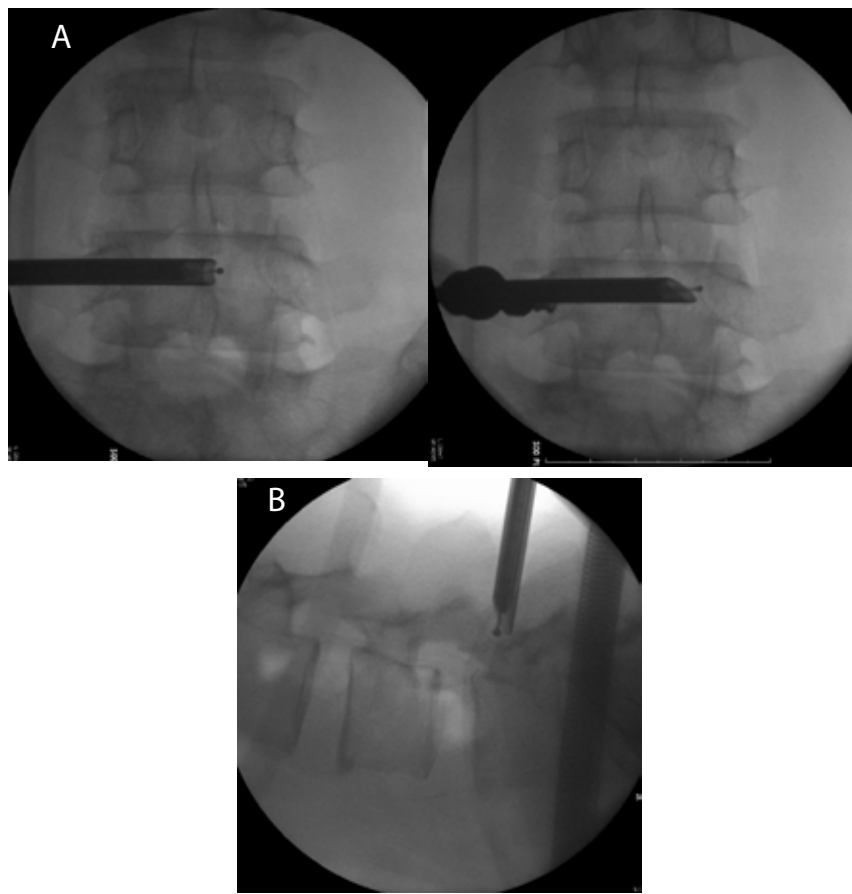

Figure12a: Showing progression of the cannula towards contra-lateral lamina.

b: Showing location of the cannula and burr for lateral recess decompression in lateral view c-arm.

(contra-lateral) side (Figure 11)

Target point - base of spinous process of proximal vertebra in AP view and posterior to the lamina in LAT view

Needle insertion - from the mentioned entry point an 18G $90 \mathrm{~mm}$ spinal needle is directed towards the base of the spinous process in slightly medial and cranial direction till it reaches the desired target point in both AP and LAT views

Serial dilation - a blunt tip guide wire is inserted and after a skin incision of approximately 9 to $10 \mathrm{~mm}$, the tract is serially dilated till the final dilator under fluoroscopic guidance (Figure 3), a circular working cannula is passed over the final dilator and the scope is passed through it.

The initial part of the procedure is similar to interlaminar for central stenosis, in which the lamina and spinous junction is identified and the base of spinous process is burred to create space to pass the cannula on the contra-lateral side. Next the cannula is slowly progressed further towards the contra-lateral facet by drilling the way across the lamina (Figure 12a and b). Flavum needs to be kept intact so as to avoid damaging the thecal sac. On reaching the facet the bony decompression is performed in similar fashion using a drill or a shaver. The rest of the procedure is similar to interlaminar ipsilateral approach (mentioned above).

In our opinion the main advantage of using contra-lateral approach is the angulation with which we can approach the facet joint that helps us to slide the cannula underneath it. This way we can perform targeted decompression of the most pathological portion of the facet i.e. ventral and medial portion of superior articular process (SAP) and preserve the rest of the facet. Secondly in our experience the isolation of the root is also fairly easy and pain free, if the procedure is done under conscious sedation. And as already mentioned we can also do central decompression in addition to lateral recess decompression (Figures 13, $14 \mathrm{a}$ and $14 \mathrm{~b})$.

\section{Foraminal stenosis}

The spinal nerve roots exit through the intervertebral foramina and the proportion between the size of the foramen and the relative space occupied by the root determines the chance of root compression in the intervertebral foramen. The intervertebral foramen has, as part of its boundaries, two movable joints intervertebral joint anteriorly and zygapophyseal joint posteriorly. The compact bone of the deep arches of the inferior vertebral notch of the vertebra above and the shallow superior vertebral notch of the vertebra below form the superior and inferior boundaries respectively [23]. The etiology of the foraminal stenosis includes SAP hypertrophy, or flavum hypertrophy, or the combination of

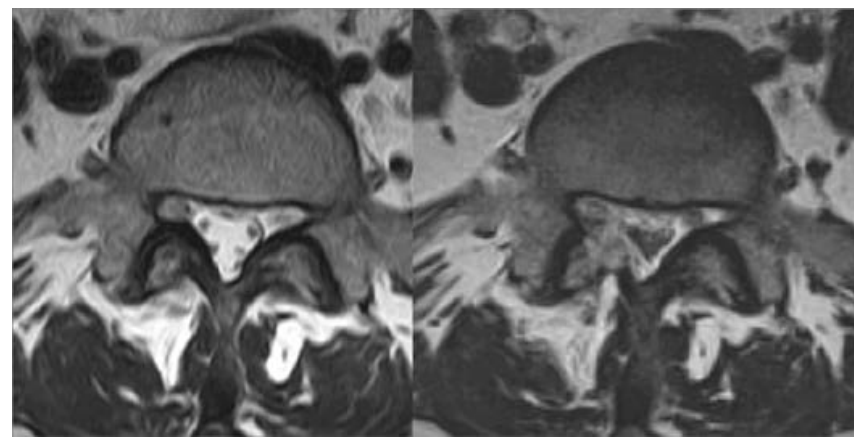

Figure13: Lateral recess stenosis pre and post-operative, interlaminar approach
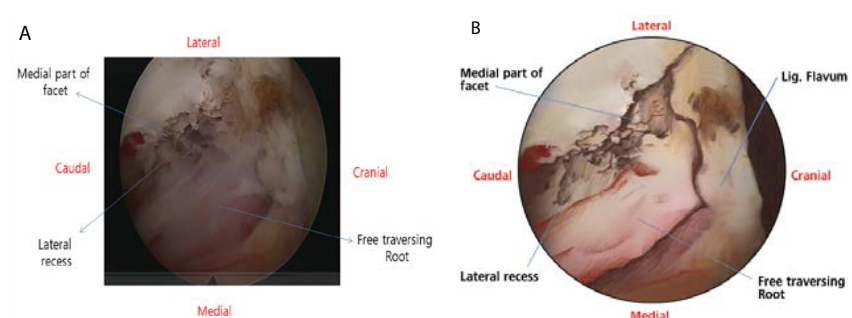

Figure 14a: Showing endoscopic view of decompressed traversing root after lateral recess decompression.

b: Showing endoscopic view of decompressed traversing root after lateral recess decompression. 
Citation: Choi G, Deshpande K, Asawasaksakul A, Lee SH (2014) New Era of Percutaneous Endoscopic Lumbar Surgery: Lumbar Stenosis Decompression - A Technical Report. J Spine 3: 182. doi:10.4172/2165-7939.1000182

both with or without a ruptured disc.

\section{Technique - Foraminoplasty}

Anesthesia - conscious sedation

Position - prone with hips and knees in flexion and abdomen supported over bolsters with the surgeon standing on the symptomatic side

Level marking - target level endplates are marked and a line is drawn extending laterally from the SP at the level of the target disc.

Entry point - calculated on pre-op MR or CT axial images targeting the foramen and avoiding the contents of the peritoneum

Target point - base of SAP in AP and anterior margin of facet joint in LAT view (Figure 15)

Skin and intermuscular infiltration - $1 \%$ lidocaine is used approximately $3 \mathrm{cc}$ for skin with $24 \mathrm{G}$ needle and 6-7 cc for intermuscular plane delivered using a $23 \mathrm{G}$ spinal needle

Needle entry - an 18G $120 \mathrm{~mm}$ spinal needle is directed towards the target point under fluoroscopic AP and LAT views and in slightly cranial to caudal angulation. An alternative method is to use tunnel view on c-arm, in this method the c-arm is tilted in medial-lateral plane to open out the facet joint on the symptomatic side, which usually is around 35 to 40 degrees. And the needle is directed towards the SAP keeping the long axis of the needle parallel to the c-arm angulation. The needle is usually progressed further to anchor it within the disc and a blunt tip guide wire is passed through it.

The tract is dilated using a single blunt dilator with tapering mouth and a beveled cannula is passed over it up to the foramen. After soft tissue clearance the facet joint is identified. The lateral capsule of the joint is cleared using the RF cautery and superior facet is drilled using the endo-drill (Figures 16 and 17). Bony bleeding usually encountered at this stage can be controlled by regulating the flow of the irrigation fluid. The drill is moved in cranial to caudal axis to decompress the foramen. The position of the drill tip can be confirmed in between with reference to the lower pedicle on AP view. The superior and medial portion of the pedicle can also be included in the decompression zone depending on the amount of stenosis. After bony decompression medial foraminal ligaments and flavum are visualized. This soft tissue decompression can be performed using a punch or a laser (Figures 18 and 19). Beyond the flavum lies the traversing root surrounded by epidural fat and blood vessels. Free disc fragment, if any, can be seen and easily removed at this stage. Free movement of the traversing root and thecal sac mark the end point of decompression (Figures 20 and 21). Wound is closed with a single skin suture with or without hemo-vac drain (Figure 22).

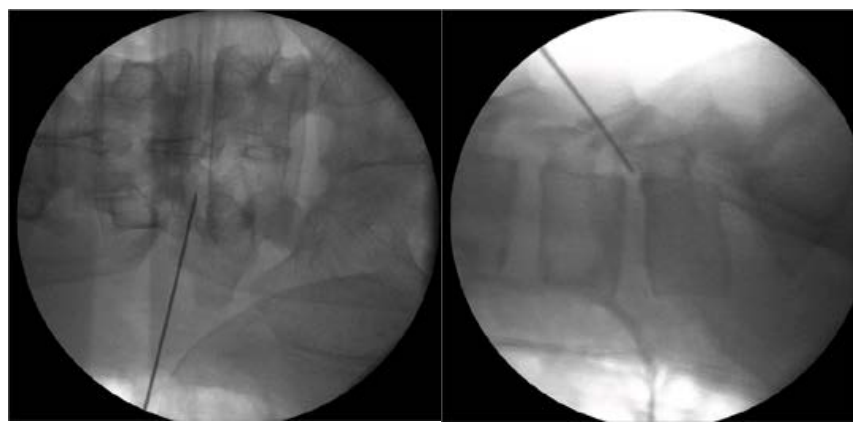

Figure 15: Target point for needle in foraminoplasty in AP \& LAT view.
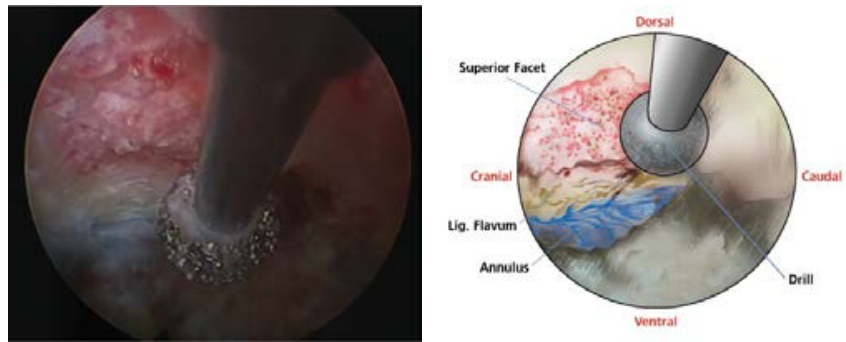

Figure16: Endoscopic view of use of diamond burr in foraminoplasty.

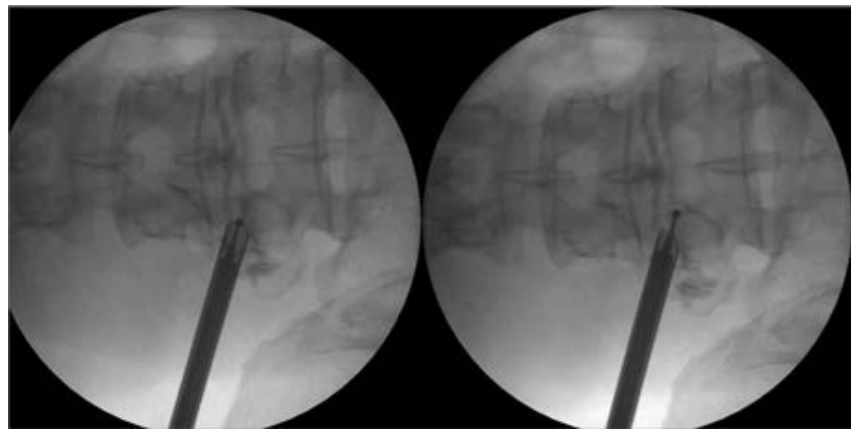

Figure17: Progression of drill in foraminoplasty.
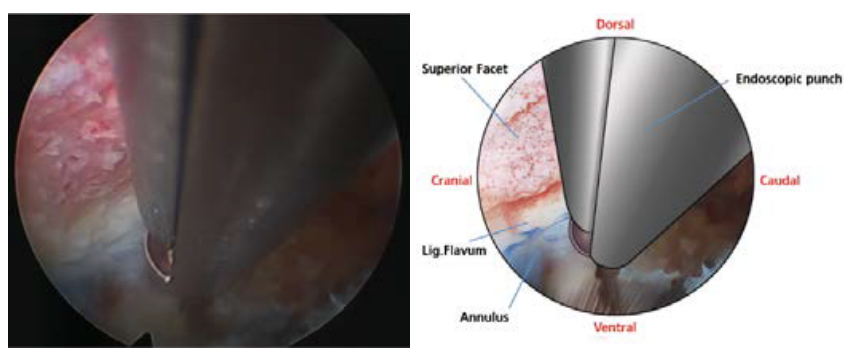

Figure 18: Endoscopic view of use of punch in foraminoplasty.
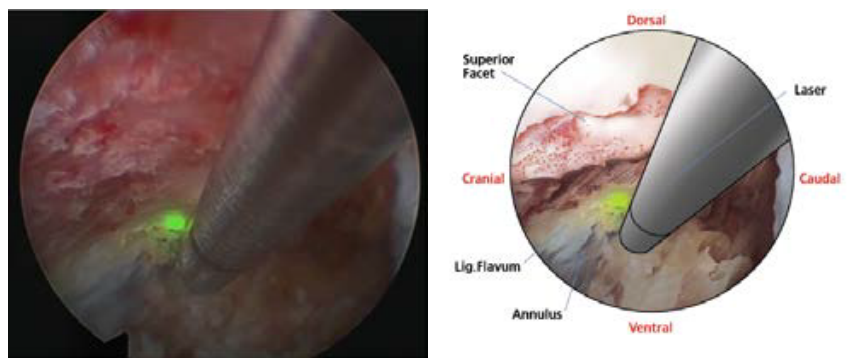

Figure19: Endoscopic view of use of laser in foraminoplasty.
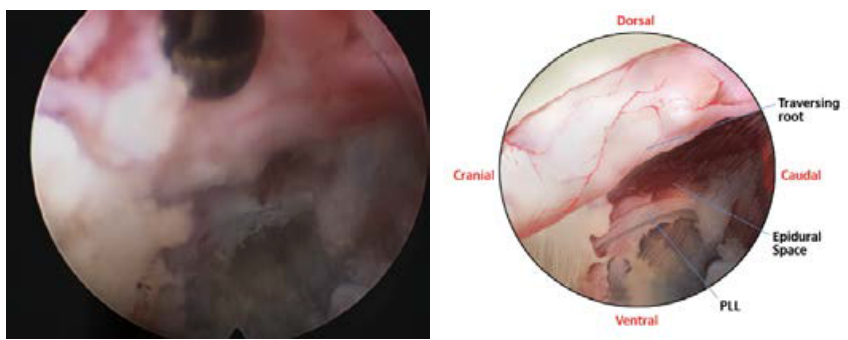

Figure 20: Endoscopic view of free traversing root after foraminoplasty. 


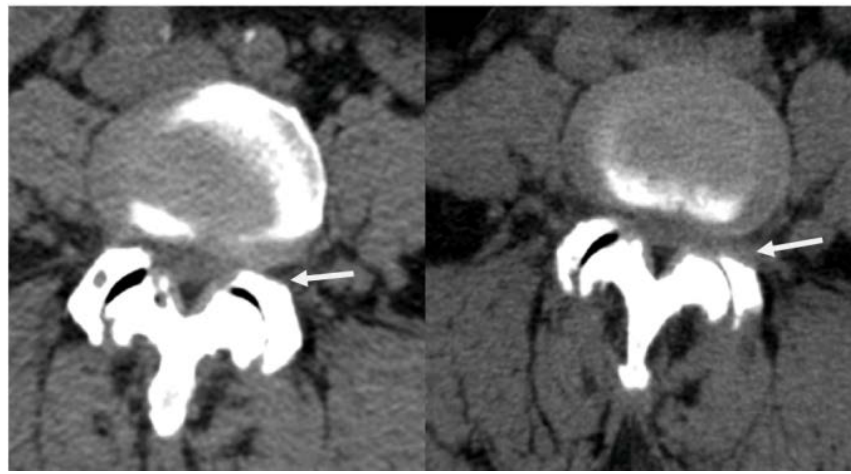

Figure 21: Pre and post operative CT images in transforaminal foraminoplasty.

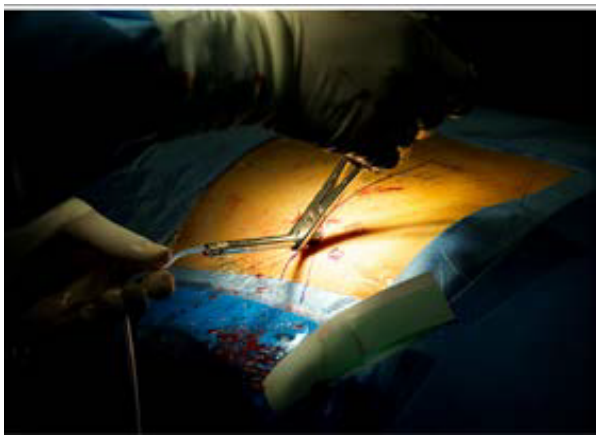

Figure 22: Drain insertion.

If hemo-vac drain is used it can be removed after 4 to 6 hours.

\section{Review of Literature}

\section{Central stenosis}

In treating a central stenotic patient, at present, there are still very few published studies that mention about effectiveness of percutaneous endoscopic technique in treating this pathology. In 2011, Komp et al. [24] reported the use of endoscopic interlaminar decompression technique in treating 72 central lumbar stenotic patients. Their successful rate for completely alleviating pain was $70.8 \%$ and they obtained high satisfaction rate $(86.5 \%)$ after 2 -year follow-up by using full-endoscopic unilateral approach for bilateral decompression. For the use of transforaminal approach, Leu H et al. in 1991, Savitz MH et al. in 1997, and Chiu JC [25-27] in 2004 also reported the successful use of this approach in central stenosis related to disc herniation but not dedicated to stenotic subgroup.

From the data available to date, we still cannot compare the result of this procedure (both interlaminar and transforaminal) to an open decompression procedure.

\section{Lateral stenosis}

There are many entities that lead to lateral recess stenosis such as thickening of ligamentum flavum or hypertrophy of facet joint that are often seen in degenerative disease [28,29] together with bulging of intervertebral disc from posterolateral margin of posterior longitudinal ligament and/or calcification of surrounding soft tissue structure such as in DISH disease [22]. The treatment of this type of stenosis is to decompress traversing root by removal of compressive cause (medial facetectomy, discectomy, flavectomy) together with indirect decompression such as laminectomy or laminotomy. In open surgery, a satisfactory outcome can be obtained in $79-93 \%$ of patients [30] For percutaneous endoscopic decompression, the results regarding interlaminar and transforaminal technique, satisfactory outcome can be obtained in $89-92 \%$ and $82 \%$ of patients respectively $[24,28,29]$.

\section{Foraminal stenosis}

Foraminal stenosis is the least tolerable type of spinal stenosis due to pronounced radicular symptom that lead to patient seeking immediate medical intervention. This type of stenosis also can be managed well by using focal decompression concept [31]. An open foraminotomy together with fusion is still the gold standard in this type of stenosis, but this surgery may lead to unnecessary fusion and iatrogenic instability in adjacent levels in future. This will also increase the incidence of dysesthesia caused by dorsal root ganglion manipulation $[30,32,33]$.

Since the introduction of percutaneous endoscopic procedure in 1990s, the option in treating foraminal stenosis by adopting MISS concept is well spread. Knight et al. in 1998 was the first to establish endoscopic foraminoplasty using laser $[34,35]$ and this procedure begin to develop afterward. Yong Ahn et al. have established the technique for L5-S1 foraminal and lateral zone stenosis $[12,36]$.

\section{Comments}

As of today, for lumbar spinal stenosis, in our practice, the number of open surgeries outnumbers the endoscopies mainly due to chronicity of the pathology and more operative time needed for endoscopy. But the indications are definitely on the rise. Proper selection of the patients is the most important predictor for better prognosis. In our view for a spine surgeon having experience in open spine decompression procedure, the interlaminar approach is fairly simple technique due to familiarity of approach and anatomy, transforaminal approach however, may need special learning and proper guidance.

With further advancement in instrumentation like wider working channel endoscope, better drilling system we can reduce the surgical time and provide better relief with minimal collateral damage and endoscopy would become the gold standard for the treatment of canal stenosis in the near future.

\section{References}

1. Weinstein JS, Burchiel KJ (2009) Dandy'S disc. Neurosurgery 65: 201-205.

2. Lee Sang-Ho Minmally Invasive Spine Surgery and Techniques 1st edition 2012

3. Smith L, Brown JE (1967) Treatment of lumbar intervertebral disc lesions by direct injection of chymopapain. J Bone Joint Surg Br 49: 502-519.

4. Hijikata S, Yamagishi M, Nakayama T (1975) Percutaneous nucleotomy: a new treatment method for lumbar disc herniation. J Toden Hosp 5: 5-13.

5. Maroon JC, Onik G (1987) Percutaneous automated discectomy: a new method for lumbar disc removal. Technical note. J Neurosurg 66: 143-146.

6. Kambin P, Sampson S (1986) Posterolateral percutaneous suction-excision of herniated lumbar intervertebral discs. Report of interim results. Clin Orthop Relat Res : 37-43.

7. Kambin P (1991) Arthroscopic microdiskectomy. Mt Sinai J Med 58: 159-164.

8. Lee SH, Lee SJ, Park KH, Lee IM, Sung KH, Kim JS et al. (1996) Comparison of percutaneous manual and endoscopic laser discectomy with chemonucleolysis and automated nucleotomy. Orthopade 25: 49-55.

9. Ditsworth DA (1998) Endoscopic transforaminal lumbar discectomy and reconfiguration: a postero-lateral approach into the spinal canal. Surg Neurol 49: 588-597.

10. Kambin P, Casey K, O'Brien E, Zhou L (1996) Transforaminal arthroscopic decompression of lateral recess stenosis. J Neurosurg 84: 462-467.

11. Knight MT, Goswami A, Patko JT, Buxton N (2001) Endoscopic foraminoplasty: 
Citation: Choi G, Deshpande K, Asawasaksakul A, Lee SH (2014) New Era of Percutaneous Endoscopic Lumbar Surgery: Lumbar Stenosis Decompression - A Technical Report. J Spine 3: 182. doi:10.4172/2165-7939.1000182

Page 8 of 8

a prospective study on 250 consecutive patients with independent evaluation. J Clin Laser Med Surg 19: 73-81.

12. Ahn Y, Lee SH, Park WM, Lee HY (2003) Posterolateral percutaneous endoscopic lumbar foraminotomy for L5-S1 foraminal or lateral exit zone stenosis. Technical note. J Neurosurg 99: 320-323.

13. Choi G, Lee SH, Raiturker PP, Lee S, Chae YS (2006) Percutaneous endoscopic interlaminar discectomy for intracanalicular disc herniations at L5S1 using a rigid working channel endoscope. Neurosurgery 58: ONS59-68.

14. Choi G, Prada N, Modi HN, Vasavada NB, Kim JS, et al. (2010) Percutaneous endoscopic lumbar herniectomy for high-grade down-migrated L4-L5 disc through an L5-S1 interlaminar approach: a technical note. Minim Invasive Neurosurg 53: 147-152.

15. Choi G, Lee SH, Lokhande P, Kong BJ, Shim CS, et al. (2008) Percutaneous endoscopic approach for highly migrated intracanal disc herniations by foraminoplastic technique using rigid working channel endoscope. Spine (Phila Pa 1976) 33: E508-515.

16. Choi G, Lee SH, Bhanot A, Raiturker PP, Chae YS (2007) Percutaneous endoscopic discectomy for extraforaminal lumbar disc herniations: extraforaminal targeted fragmentectomy technique using working channel endoscope. Spine (Phila Pa 1976) 32: E93-99

17. Kim JS, Choi G, Lee SH (2011) Percutaneous endoscopic lumbar discectomy via contralateral approach: a technical case report. Spine (Phila Pa 1976) 36: E1173-1178.

18. Choi G, Kim JS, Lokhande P, Lee SH (2009) Percutaneous endoscopic lumbar discectomy by transiliac approach: a case report. Spine (Phila Pa 1976) 34 E443-446.

19. Choi G, Lee SH, Deshpande K, Choi H (2014) Working channel endoscope in lumbar spine surgery. J Neurosurg Sci 58: 77-85.

20. Ahn Y (2014) Percutaneous endoscopic decompression for lumbar spinal stenosis. Expert Rev Med Devices.

21. Andreisek G, Deyo RA, Jarvik JG, Porchet F, Winklhofer SF, et al. (2014) Consensus conference on core radiological parameters to describe lumbar stenosis - an initiative for structured reporting. Eur Radiol .

22. Karpman RR, Weinstein PR, Gall EP, Johnson PC (1982) Lumbar spina stenosis in a patient with diffuse idiopathic skeletal hypertrophy syndrome. Spine (Phila Pa 1976) 7: 598-603.
23. Devi R, Rajagopalan N. Morphometry of lumbar intervertebral foramen. Indian J Orthop 2005;39:145-7

24. Ruetten S, Komp M, Merk H, GodoliasG (2009) Surgical treatment for lumbar lateral recess stenosis with the full-endoscopic interlaminar approach versus conventional microsurgical technique: a prospective, randomized, controlled study. J Neurosurg Spine10: 476-485.

25. Leu H, Schreiber A (1991) [Percutaneous nucleotomy with disk endoscopy-a minimally invasive therapy in non-sequestrated intervertebral disk hernia] Schweiz Rundsch Med Prax 80: 364-368.

26. Savitz MH (1997) Soft disc herniation in patients with lumbar stenosis Neurosurg Focus 3: e7.

27. Chiu JC (2004) Evolving transforaminal endoscopic microdecompression for herniated lumbar discs and spinal stenosis. Surg Technol Int 13: 276-286.

28. Ruetten S, Komp M, Hahn P, Oezdemir S (2013) [Decompression of lumbar lateral spinal stenosis: full-endoscopic, interlaminar technique]. Oper Orthop Traumatol 25: 31-46.

29. Kambin P, Casey K, O’Brien E, Zhou L (1996) Transforaminal arthroscopic decompression of lateral recess stenosis. J Neurosurg 84: 462-467.

30. Postacchini $F$ (1999) Surgical management of lumbar spinal stenosis. Spine (Phila Pa 1976) 24: 1043-1047.

31. Jenis LG, An HS (2000) Spine update. Lumbar foraminal stenosis. Spine (Phila Pa 1976) 25: 389-394

32. Darden BV 2nd, Wade JF, Alexander R, Wood KE, Rhyne AL 3rd, et al. (1995) Far lateral disc herniations treated by microscopic fragment excision. Techniques and results. Spine (Phila Pa 1976) 20: 1500-1505.

33. Hodges SD, Humphreys SC, Eck JC, Covington LA (1999) The surgical treatment of far lateral L3-L4 and L4-L5 disc herniations. A modified technique and outcomes analysis of 25 patients. Spine (Phila Pa 1976) 24: 1243-1246.

34. Knight MT, Vajda A, Jakab GV, Awan S (1998) Endoscopic laser foraminoplasty on the lumbar spine--early experience. Minim Invasive Neurosurg 41: 5-9.

35. Knight M, Goswami A (2003) Management of isthmic spondylolisthesis with posterolateral endoscopic foraminal decompression. Spine (Phila Pa 1976) 28 573-581.

36. Daniel H Kim, Gun Choi, Lee Sang-Ho. Endoscopic spine procedures 1st edition 2011. 